05

\title{
Наносекундная динамика разрушения напряженного гранита под влиянием ударной волны
}

\author{
(С) И.П. Щербаков, В.И. Веттегрень, Р.И. Мамалимов, Х.Ф. Махмудов \\ Физико-технический институт им. А.Ф. Иофрфе РАН, \\ 194021 Санкт-Петербург, Россия \\ ฯ e-mail: Victor_Vettegren@mail.iofffe.ru \\ (Поступило в Редакцию 20 октября 2016 г.)
}

\begin{abstract}
Методом люминесценции с временны́м разрешением $2 \mathrm{~ns}$ исследована динамика разрушения поверхности одноосно сжатого гранита под влиянием ударной волны, вызванной электрическим разрядом в воздухе около его поверхности. Воздействие волны вызывает вылет струй положительно заряженных ионов из наиболее искаженных областей на поверхности образца. Обнаружено, что при достижении величины сжимающих напряжений значения $\sim(0.92-0.95)$ от прочности образца, на временно́й зависимости интенсивности струй наблюдается 2 максимума: первый - когда ударная волна достигает поверхности образца, а второй — когда через образец проходит разрушающая трещина.
\end{abstract}

DOI: 10.21883/JTF.2017.08.44724.2075

\section{Введение}

В последние годы нами были начаты экспериментальные исследования механизма разрушения ненагруженных гетерогенных материалов - горных пород под воздействием ударных волн. Было установлено [1-4], что микроразрушение кварца и гранитов достигается за счет испарения положительно заряженных ионов. В настоящей работе в отличие от вышеупомянутых исследований образцы подвергали воздействию одноосного сжимающего напряжения. Кроме того, временно́е разрешение было увеличено в 5 раз - с 10 до $2 \mathrm{~ns}$, что позволило более детально, чем ранее, исследовать динамику разрушения.

\section{Методика эксперимента}

Для исследований был выбран образец гранита с содержанием кварца $\sim 30 \mathrm{vol} . \%$ и полевого шпата $\sim 70 \mathrm{vol} \%$. Он представлял собой параллелепипед с размерами ребер $L=20 \times 20 \times 40 \mathrm{~mm}$, внутри которого был вырезан паз, в который были вставлены медные электроды, присоединенные к конденсатору. При разряде конденсатора между электродами возникала дуга. Она вызывала появление ударной волны в воздухе и вслед за ней - в образце [5]. Энергия разряда составляла $\sim 0.2 \mathrm{~J}$, а мощность $-2 \cdot 10^{5} \mathrm{~W}$.

Ионы в струях ионов находятся в электронно-возбужденном состоянии. При переходе из возбужденного в основное состояние они излучают свет в видимой области спектра, т.е. возникает фрактолюминесценция (FL). Для ее регистрации перед поверхностью гранита устанавливали один из концов кварцевого световода, а второй конец располагали перед поверхностью фотокатода фотоэлектронного умножителя РМТ-136. Разряд приводил к колебаниям образца гранита, которые регистрировали используя датчик из пьезокерамики ЦТС-19 (размеры датчика $-4 \times 4 \times 1 \mathrm{~mm})$. Напряжения на пьезокерамике и выходе РМТ подавали на вход аналогового цифрового преобразователя ADS-3112 и через каждые $2 \mathrm{~ns}$ записывали в память компьютера для дальнейшего анализа и обработки.

Для сжатия образцов использовали пресс PGDR. Величину сжимающего напряжения изменяли ступенчато - через 10-20 МРа. На каждой ступени записывали временны́е зависимости интенсивности люминесценции. Разрушающее напряжение исследованного образца гранита до воздействия ударной волны $P_{f} \approx(280 \pm 10) \mathrm{MPa}$.

\section{Временны́е зависимости люминесценции}

Через $24 \mathrm{~ns}$ после замыкания конденсатора происходит ионизация воздуха и пробой промежутка между электродами. Это явление длится $\sim 2 \mathrm{~ns}$ и приводит к мощным электромагнитным помехам (рис. 1).

Через $\sim 26$ ns загорается дуга (рис. 2). Ее излучение достигает максимального значения через $\sim 80 \mathrm{~ns}$, а затем уменьшается приблизительно экспоненциально от времени. Через $\sim 1 \mu$ s интенсивность дуги становится пренебрежимо малой.

Под влиянием дуги в образце формируется ударная волна, которая вызывает колебания образца. Через $\sim 3 \mu$ s после возгорания дуги ударная волна достигает поверхности образца и отражается от нее. Многочисленные отражения от граней поверхности образца приводят к его вынужденным нерегулярным колебаниям (рис. 3).

Каждое отражение волны от поверхности образца вызывает появление многочисленных струй ионов (рис. 4,5$)$. Их интенсивность варьирует на 1-2 порядка.

Когда величина сжимающего напряжения достигает значения $\sim(0.92-0.95)$ от прочности гранита, число 
струй возрастает на порядок (рис. 5), а временно́й интервал между ними уменьшается. На временно́й зависимости появляются два максимума, в которых число

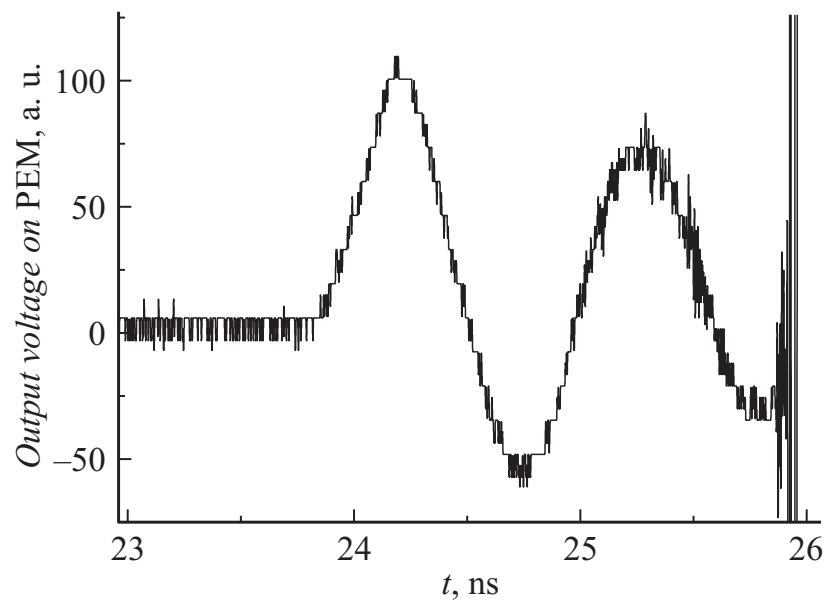

Рис. 1. Электромагнитные помехи при пробое воздуха между электродами около поверхности образца.

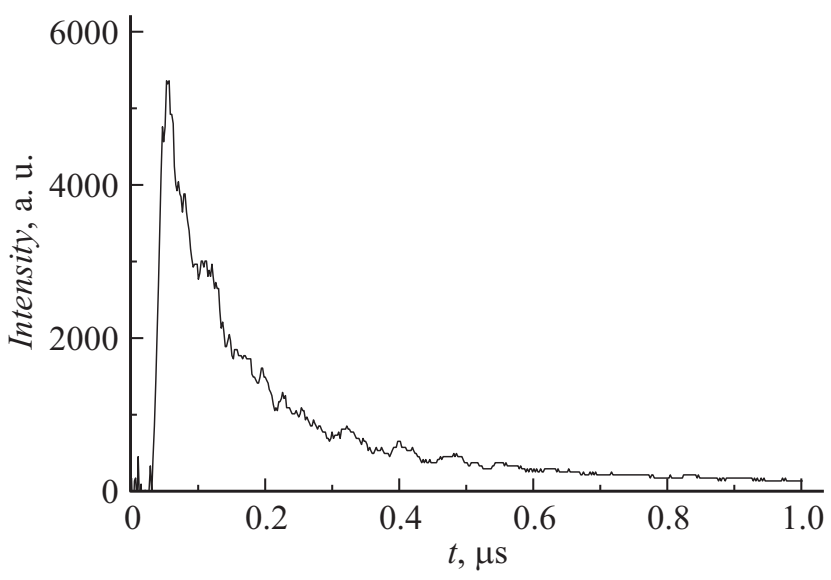

Рис. 2. Временна́я зависимость интенсивности излучения дуги.

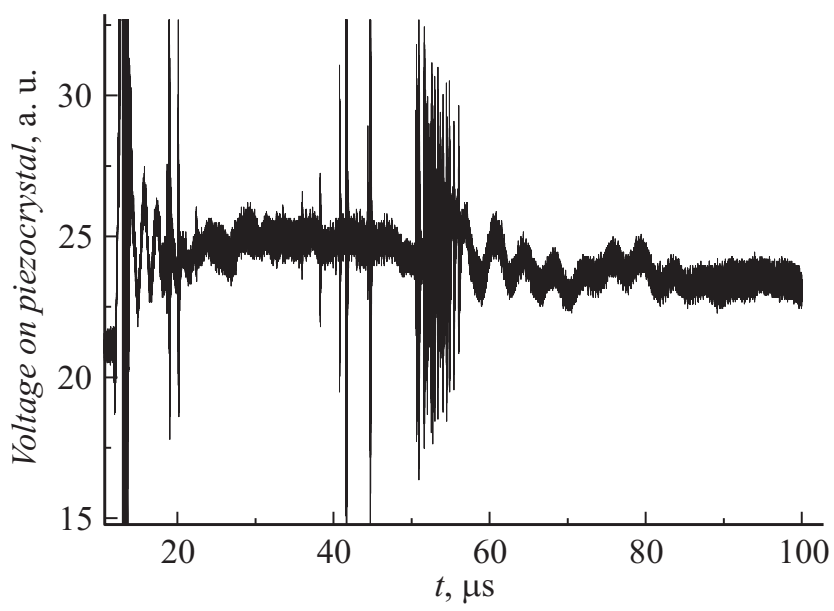

Рис. 3. Вынужденные колебания поверхности образца при отражении ударной волны от его границ.

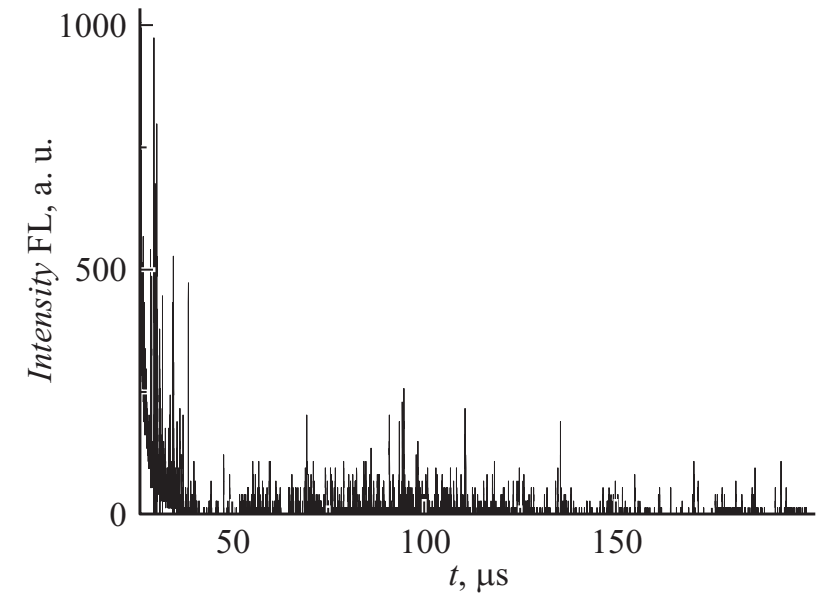

Рис. 4. Временна́я зависимость интенсивности FL поверхности образца гранита при сжимающем напряжении $P \sim 14 \mathrm{MPa}=0.5 P_{f}$

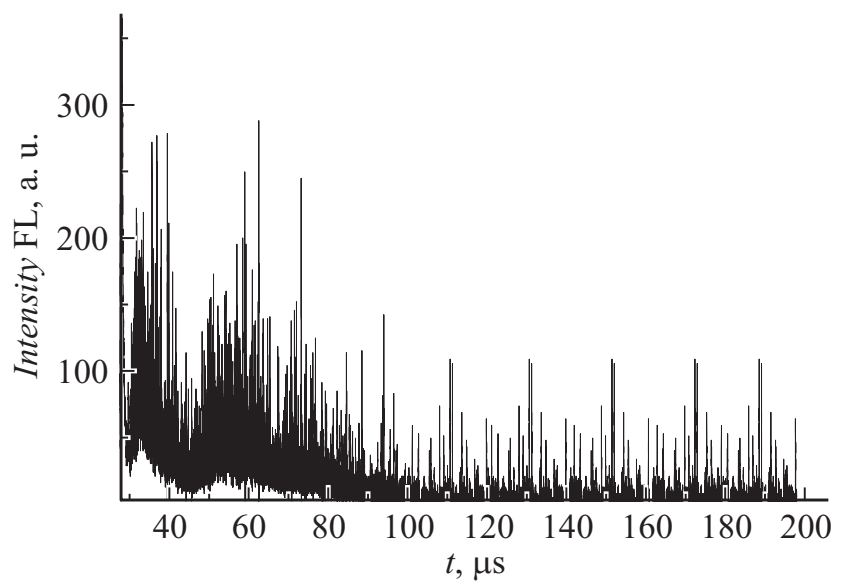

Рис. 5. Временна́я зависимость интенсивности FL поверхности образца гранита при сжимающем напряжении $P \sim 26 \mathrm{MPa}=0.92 P_{f}$.

струй ионов в единицу времени наибольшее. Первый максимум возникает в момент, когда ударная волна достигает поверхности образца, т.е. через $\sim 33 \mu \mathrm{s}$, а второй через $\sim 56 \mu \mathrm{s}$, когда через образец проходит трещина, рассекающая его на две половины (рис. 6).

\section{Обсуждение результатов}

Механизм образования струй положительных ионов под действием механических напряжений был предложен в [6,7]. Согласно этим исследованиям, при пересечении дислокациями, движущимися в разных плоскостях скольжения, кристаллическая решетка искажается настолько, что электронные уровни основного и возбужденного состояний могут пересекаться. Это может приводить к переходу между ними и последующему распаду межатомных связей, при котором из мест пересечения 


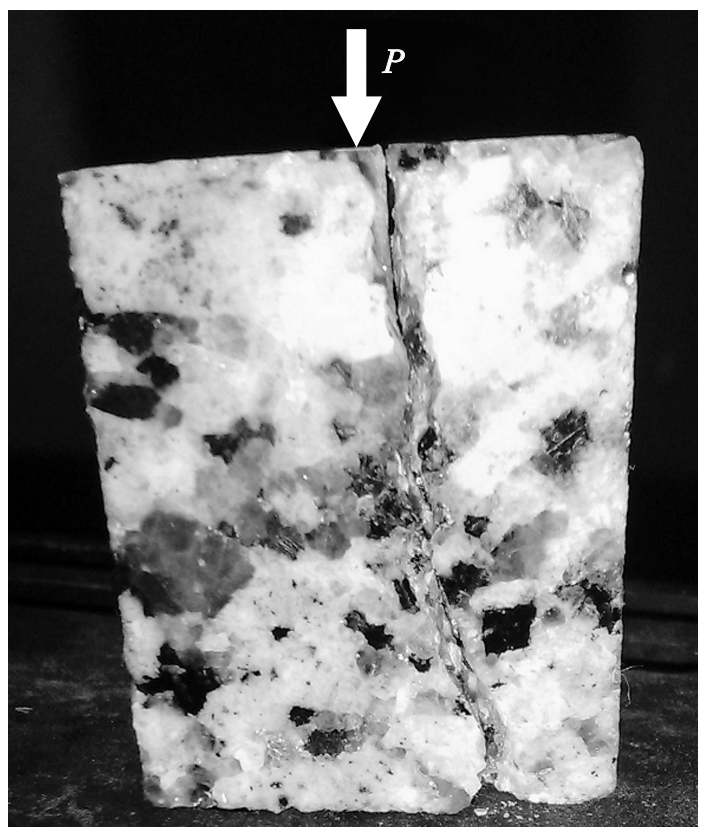

Рис. 6. Фотография образца разрушенного образца гранита.

дислокаций должны вылетать положительно заряженные ионы.

Известно [8], что дислокации, движущиеся в пересекающихся плоскостях скольжения, наталкиваются друг на друга, что приводит к возникновению стопоров, препятствующих их движению. В $[9,10]$ показано, что после разрушения стопоров возникают мельчайшие (с линейными размерами до $\sim 10^{2} \mathrm{~nm}$ ) микротрещины, получившие название ,зародышевых“.

По-видимому, каждая вспышка FL возникает при образовании зародышевой микротрещины. Выше уже отмечалось, что интенсивность струй ионов изменяется на два порядка. По-видимому, такая вариация интенсивности вспышек отражает вариацию размеров зародышевых микротрещин.

Когда величина сжимающего напряжения мала $P<(0.92-0.95) P_{f}$, струи ионов вылетают из мест пересечений дислокаций, существовавших на поверхности гранита до его нагружения.

При $P \sim(0.92-0.95) P_{f}$ образец начинает пластически деформироваться. Пластическая деформация осуществляется за счет размножения и движения дислокаций. Число дислокаций, движущихся в пересекающихся плоскостях скольжения в поверхностном слое гранита, возрастает. Ударная волна способствует прорыву стопоров, что и влечет за собой резкое увеличение числа вылетающих струй ионов. По-видимому, наибольшее число стопоров прорывается, когда ударная волна первый раз достигает поверхности образца, т. е. через $\sim 33 \mu$ s после возгорания дуги.

Согласно [11], когда концентрация зародышевых микротрещин достигает критического значения, образуется макротрещина. Вероятно, $56 \mu$ s после возгорания дуги как раз и отвечает моменту объединения зародышевых трещин.

\section{Заключение}

Ударная волна, вызванная электрическим разрядом, около поверхности образца гранита способствует разрушению стопоров, препятствующих движению дислокаций в пересекающихся плоскостях скольжения. При разрушении стопоров из образца вылетают положительно заряженные ионы. Одновременно образуются очаги разрушения, вероятно, зародышевые трещины. Накопление таких трещин ведет к появлению макротрещины и разрушению образца.

Работа выполнена при финансовой поддержке Российского фонда фундаментальных исследований (грант № 16-05-00138).

\section{Список литературы}

[1] Веттегрень В.И., Воронин А.В., Куксенко В.С., Мамалимов Р.И., Щербаков И.П. // ФТТ. 2014. Т. 56. Вып. 2. C. 315-317.

[2] Веттегрень В.И., Щербаков И.П., Воронин А.В., Куксенко В.С., Мамалимов Р.И. // ФТТ. 2014. Т. 56. Вып. 5. C. $981-985$.

[3] Веттегрень В.И., Щербаков И.П., Куксенко В.С., Мамалимов Р.И. // ФТТ. 2014. Т. 56. Вып. 9. С. 1767-1771.

[4] Веттегрень В.И., Куксенко В.С., Щербаков И.П. // Физика Земли. 2016. № 5. С. 134-149.

[5] Абрамова К.Б., Щербаков И.П., Русаков А.И. // ЖТФ. 1999. Т. 69. Вып. 2. С. 137-140.

[6] Zakrevskii V.A., Shuldiner A.V. // Phil. Mag. 1995. Vol. B.71. N 2. P. $127-138$.

[7] Закревский В.А., Шульдинер А.В. // ФТТ. 2000. Т. 42. Вып. 2. С. 263-266.

[8] Cottrell A.H. Theory of Crystal Dislocations. NY.: Gordon and Breach, 1964. $91 \mathrm{p}$.

[9] Черемской П.Г., Слезов В.В., Бетехтин В.И. Поры в твердом теле. М.: Энергоатомиздат, 1990. $374 \mathrm{c.}$

[10] Бетехтин В.И., Кадомцев А.Г. // ФТТ. 2005. Т. 47. Вып. 5. C. 801.

[11] Петров В.А., Башкарев А.Я., Веттегрень В.И. Физические основы прогнозирования разрушения конструкционных материалов. СПб.: Политехника, 1993. 475 с. 